camera on the polar axis of a siderostat, and driving it by clockwork. In this way each plate could be exposed for forty minutes without any intervention on the part of the observer; but little result was obtained, in consequence, most probably, of the great amount of dew that was deposited on the lens.

Five plates exposed on the $12 \mathrm{th}$, between $12 \mathrm{~h} .55 \mathrm{~m}$. a.m. and 4 h. $8 \mathrm{~m}$. a.m.-Greenwich mean time - showed no trace whatever of any meteor ; and eye observations made during the same interval, but with occasional breaks, were not very fruitful as regards results, only about twenty meteors in all being recorded, and not even all these Leonids. The evening of the I 4 th was very cloudy, but towards midnight the weather cleared, and turned out eventually very fine. Four plates were exposed consecutively between Ih. $20 \mathrm{~m}$. a.m. and $4 \mathrm{~h}$. $20 \mathrm{~m}$., but no trail was caught, although a few trails were observed to pass in the range of the wide-angle lens. It was found, however, impossible to keep the moisture away, although special precautions were taken on this evening to shield the lens. More strict attention was paid, however, to eye observations, and an almost continuous watch during the interval (three hours), mentioned above, was not devoid of results. In all, thirty-two meteors were seen : nineteen of these were judged as Leonids, ten as Andromedes, and two as sporadic. At $2 \mathrm{~h} .37 \mathrm{~m}$. a.m. a fine meteor was observed to pass a little to the north, and parallel to the belt, of Orion. Five short trails of distinct Leonids were observed near the radiant point. The most brilliant meteor of the evening, or rather of the morning, was that which appeared at $4 \mathrm{~h}$. $17 \mathrm{~m}$. a.m. Commencing in the northern part of the constellation of Hydra (about $\zeta$ Hydra), it moved in the direction of Jupiter, passing a little to the south of Regulus, skirting $i$ Leonis, and vanishing near $\zeta$ Ursæ Majoris. Its trail must have been quite $45^{\circ}$ in length, being brilliant with a bright stellar nucleus. As this meteor's path was included in the region that was being photographed at the time of its appearance, it was a great surprise to find no sign of its trail on the plate. The general idea gathered from these two watches was that the Leonids were not more abundant than usual ; in fact, one was surprised at the apparent.deanth of these bodies. W. J. S. L.OCKYER.

Almost exactly at I I p.m., on November I 2, I896, I saw in the east a remarkable meteor. Castor and Pollux were practically in a vertical line, and the meteor appeared a short distance below Pollux, moving horizontally in a direction from right to left (south to north, as it were), at right angles to a line produced through the stars named. Curiously enough, the produced path of the meteor would lead to a position not far fron: the radiant point of the Leonids ; but the direction of motion was centripetal, not centrifugal, as regards this radiant. The bright head of the meteor was soon extinguished, leaving behind it a very beautiful evanescent trail of tiny purple sparks. I saw no meteors coming from the radiant in Leo.

C. T. Whitimis.

Cardiff.

\section{THE MOUTHE CAVE.}

IN a recent number of La Revue Scientifique, an interesting account was given by $M$. Rivière of his anthropological work in connection with the "Mouthe Cave."

M. Rivière bas done much research in this direction, and chiefly in the districts of Saint-Cyprien, Bugue, and Montignac. He has explored and studied minutely the caves of Pageyral, Combarelles, and Rey, about which he hopes to publish a volume, as the excavations are now complete. During his work he has come across some very curious finds.

NO. I 4 I 2, VOL. 55]
Certainly the most interesting, because unique, cave yet visited by him is the "Mouthe Cave." It is situated near the hamlet of La Mouthe, in the neighbourhood of Saint-Cyprien, and was discovered by M. Rivière quite accidentally on September 2, 1894 . 'The cave had been emptied, as was thought, by the owner, M. Lapeyre, forty-nine years before, and had been used as a barn for storing beetroot and potatoes during the severe winter months. The rubbish cleared out of it was thrown on the neighbouring fields; it consisted chiefly of bones, teeth, and cut flints, but the latter only could be found by M. Rivière. After a lapse of half-a-century, it is not surprising that the other remains had decayed and disappeared in the soil.

Returning to the cave later, in company with M. G. Berthoumeyrou, M. Rivière found at the furthest extremity several quaternary hearths, quite untouched. On removing a little of the soil, the explorers came across reindeers' teeth and pieces of bone; also a sea-shell, with a small hole, as if it had once been bored for suspension.

The work was not continued till the following year (1895), when in April, while levelling the floor, the slope formed by the hearths was slightly disturbed, and brought to light a semicircular hole, which proved to be the opening to a very narrow passage. A few days later the passage was explored by MM. E. and G. Berthoumeyrou, but not without great difficulty, it being little more than twelve inches high and twenty inches wide. The curious drawings, described later, were not seen till a distance of ninety yards had been reached.

Later, M. Rivière had a cutting made of dimensions strictly necessary for reaching the drawings more easily, and ascertaining the different epochs at which the cave was inhabited.

In the middle of July, some results of the excavations were sent to the Academy of Sciences, consisting chiefly of rubbings of a drawing of an animal resembling a bison or auroch. Three weeks later M. Rivière returned to La Mouthe, in order to commence a thorough and methodical exploration of the cave. All the earth, on being taken from the cave, was carefully sifted, so that nothing should be lost ; bones, teeth, and flints were found. The work lasted a month, and was taken up in March and April of this year, and again in August and September.

The cave is at an altitude of about 200 yards, and 130 yards above the railway, which is about two miles away. It is situated at the top of a hill, the semicircular entrance being nearly eleven yards wide and a little over three yards high. The hamlet of $\mathrm{La}$ Mouthe is about 320 yards away, and the orientation of the care is eastsouth-east. The rock is of very impure limestone, mixed with clay, and containing grains of quartz.

The following are the results at which M. Rivière has arrived concerning the age and former inhabitants of the cave, which has been inhabited by man at two distinct epochs.

(I) At the Neolithic epoch, since the upper surface is formed entirely of hearths containing cinders and coal, with bones of animals belonging to the present geological epoch, numerous pieces of coarse pottery, human bones, of which some seem to have belonged to one person, besides a good number of cut flints.

(2) At the Quaternary epoch, geologically speaking, for this upper surface rests on a fairly thick stalagmite which separates it from hearths which are much more ancient; the latter fact being proved by the fauna found by M. Rivière (Ursus spelæus, Hyæna, \&c.). In this underlayer many cut flints were found, also weapons and instruments in bone. Amongst the latter may be mentioned a long fine needle, about six inches long, almost perfect; also bones engraved with figures, and teeth, bored, as if once used for amulets. No pottery, however, 
or polished flints or human bones have been found in this lower layer up to the present time.

At a short distance from the entrance the Neolithic finds cease, leaving the stalagmite uncovered; but, on the other hand, the quaternary hearths persist, and they are less dark in colour, and of reddish hue, owing to clay with which they are mixed. Further on the hearths become simple layers of clay, containing quaternary fauna and worked flints. Further on still, about seventy yards from the entrance, there is a great accumulation of remains of bears, and hyænas' teeth, \&c.

Owing to the excavations made under the direction of $M$. Rivière, it is possible to go about a length of 136 yards in the cave with perfect ease. A further distance of eighty yards may be traversed, but only by crawling, as the passage is very small.

The drawings on the sides of the cave were first noticed in April last year ; they consist generally of two kinds-some simple, made on the walls and ceiling (vault) of the cave ; others with certain features coloured with ochre. There is a third kind, consisting of a scratching of the rock, the scratches being covered also with ochre. The first and second represent animals only. In some cases it is difficult to make out what is represented; two, however, have been identified, one being a bison ; the other the hinder limbs of which seem to represent a kind of ox, while the head (of which part is effaced) resembles a horse with a short mane. It measures no less than two yards in length from the tip of its snout to the end of its tail.

The photographs of these two drawings, which were sent to the Academy, were taken by M. Charles Durand, They were obtained by means of an illumination of 140 candles, and an exposure of four and a half hours. M. Rivière and $M$. Durand hope at some future time to photograph the other engravings.

\section{HENRY NEWELL MARTIN.}

$\mathrm{H}$ ENRY NEWELL MARTIN was born on July I 1848, at Newry, Co. Down, Ireland. He was the eldest of a family of twelve, his father being at the time a Congregational minister, but afterwards becoming a schoolmaster. Both his parents were Irish, his father coming from South Ireland, and his mother from North Ireland. He received his early education chiefly at home; for though he went to several schools, his stay was not long at any one of them.

Having matriculated at the University of London before he was fully sixteen years of age (an exemption as to age being made in his favour), he became an apprentice to Dr. McDonagh, in the Hampstead Road, London, in the neighbourhood of University College, on the understanding that the performance of the services which might be required of him as apprentice, should not prevent his attending the teaching at the Medical School of the College, and the practice at the Hospital. It was here that I made his acquaintance in 1867. I was at that time teacher of histology and practical physiology at the School, having succeeded the late Dr. George Harley, and I well remember that Martin asked my permission to attend my course, in face of the drawback that, owing to his duties as apprentice above mentioned, he could only give to the study half the time demanded. I unwillingly gave permission; but soon found that Martin learnt in his half time more than the rest of the students in their whole time; and thus begun a friendship between us, which lasted until his death. During his career at University College he greatly distinguished himself, taking several medals and prizes. In I870 he obtained a scholarship at Christ's College, Cambridge, Liversidge, now Professor of Chemistry in the University of Sydney, then a student at the Royal
School of Mines, gaining one at the same time; he had, in the summer of that year, conducted at Cambridge a class of Histology for the late Sir G. Humphry. Though elected to the scholarship, Martin had some doubts whether he ought to take it up, and anxiously consulted me on the matter. I believe that my being able to tell him that I, too, was about to go to Cambridge, having been appointed Prælector of Physiology at Trinity College, finally removed all hesitation. Thus we two went up to Cambridge together in the October of that year. I at once asked him to assist me by acting as my demonstrator, and during the whole of his stay at Cambridge he was in every way my right hand. His energy and talents made my work much easier, and his personal qualities did much to make natural science popular in the 'University. At that time there was' perhaps, a tendency on the part of the undergraduate to depreciate natural and, especially, biological science, and to regard it as something not quite academical. Martin, by his bright ways won, among his fellows, sympathy for his line of study, and showed them, by entering into all their pursuits (he became, for instance, President of the Union, and Captain of the Volunteers), that the natural science student was in no respects inferior to the others.

In Cambridge, as in London, his career was distinguished. He gained the first place in the Natural Science Tripos of 1873 , the second place being taken by Francis M. Balfour; at that time the position in the Tripos was determined by the aggregate of marks in all the subjects. While at Cambridge he took the B.Sc. and M.B. London, gaining in the former the scholarship in Zoology ; he proceeded later to the D.Sc., being the first to take that degree in Physiology So soon as, or even before, he had taken his degree, he began to devote some time to research, though that time, owing to the necessity of his making money by teaching, was limited ; his first publication was a little paper on the structure of the olfactory membrane, which appeared in the Journal of Anatomy and Physiology.

In the summer of 1873 , I had assisted the late Prof. Huxley in the course of Elementary Biology which he initiated at the Royal College of Science, and in the following year I introduced a similar course into my teaching at Cambridge. In this Martin was my chief assistant ; he also subsequently acted as assistant in the same course to Prof. Huxley. One result of this was that he prepared, under Huxley's supervision, a text-book of the course which, under their names, appeared with the title "Practical Biology," and which has since been so largely used.

In 1874 he was made Fellow of his College, and giving himself up with enthusiasm to the development of natural and, especially, of biologic science at the University, was looking forward to a scientific career in England, if not at Cambridge. About that time, however, the Johns Hopkins University at Baltimore was being established, and such was the impression made by Martin upon those with whom he came in contact, among others Dr. Gilman, of Baltimore, that in 1876 he was invited to become the first occupant of the chair of Biology which had been founded in the Johns Hopkins University. This offer he accepted, and thus nearly the whole of his scientific career was passed in America. He went out prepared to develop in his new home the higher teaching of biologic science, especially that spirit of research which alone makes teaching "high"; and during the rather less than a score of years which made up his stay at Baltimore, he produced a very marked effect on American science, fully working out the great aim of the University which had adopted him. By himself, or in concert with his pupils, he carried on many important investigations, among which may especially be mentioned those on the excised mammalian heart, one of which formed the subject of the

$$
\text { NO. I } 4 \text { I 2, VOL. 55] }
$$

